\title{
The large-scale landslide on the flank of caldera in South Sulawesi, Indonesia
}

\author{
Satoshi Tsuchiya $^{1)}$,Katsuhiro Sasahara ${ }^{2)}$, Sasuhiro Shuin $^{3)}$,Shujiro Ozono ${ }^{4)}$
}

\begin{abstract}
An extraordinarily large-scale landslide with a volume of 200 million m3, a width of about 1,600 m, and a height of about $750 \mathrm{~m}$ occurred on 2004 March 26, 13:45 local time, on a steepcaldera wall on the northwest flank of Mt. Bawakaraeng $(2,830 \mathrm{~m})$ at the headwater of the Jeneberang River in South Sulawesi, Indonesia. The debris avalanche extended about $7 \mathrm{~km}$ from the headwater and buried the river valley, causing devastating damage. There are a great many calderas in the world, notably Japan. If a large-scale sector collapse were to occur in a heavily populated area, it would be a devastating disaster for the people living in the area. The aim of this paper is to outline such a landslide and explain its mechanism of occurrence. We evaluated the stability of the original slope before the landslide using the limit equilibrium method and the finite-element-based shear strength reduction method (SSRFEM) with the strength reduction factor. The limit equilibrium method showed that a rise in the groundwater level caused the landslide. Although the critical slip surface predicted by the SSRFEM was shallower than that of the actual slip surface, the end positions of the actual and predicted slip surfaces were almost the same. Moreover, the end position of the critical slip surface before the landslide -the headwater of the Jeneberang River- was a knick point at which the slope inclination became steeper. SSRFEM analysis may be useful for evaluating the slope stability of large-scale landslides, because the critical slip surface predicted by it was close to the actual surface, even though we assumed homogenous conditions without information on the degree of weathering or ground properties. As the knick point formed at the end of the critical slip surface and is equivalent to the end of the actual slip surface, we assume such topographic features to be a primary geomorphologic cause of the landslide.
\end{abstract}

Key words: large-scale landslide $\cdot$ Stability analysis $\cdot$ limit equilibrium method $\cdot$ finite element method $\cdot$ caldera $\cdot$ Indonesia

\section{Introduction}

Under certain conditions, a volcanic slope can fail catastrophically (Moon, 2002), produced debris avalanches that accelerate rapidly down slope. And large volume avalanches have traveled many tens of kilometers (Hürlimann, 1999), deposing volcanic debris tens of meters thick over area of hundreds to more than a thousand square kilometers (Siebert, 1992).

On 2004 March 26 at 13:45 local time, an extraordinarily large-scale landslide occurred on a steep wall in the northwest of Mt. Bawakaraeng (2830 m), at the headwater of the Jeneberang River in South Sulawesi, Indonesia (Figs. 1, 2). The debris avalanche extended about $7 \mathrm{~km}$ from the headwater and buried the river valley, causing devastating damage to Lenkese Village, including 32 dead and missing, the collapse or burial of 12 houses and an elementary school on the lower terrace, and the deaths of 635 head of cattle (Tsuchiya et al., 2004).

About $35 \mathrm{~km}$ downstream from the landslide, the Bili-bili multi-purpose reservoir with an effective water storage capacity of 350 million $\mathrm{m}^{3}$; supplies water for irrigation, domestic uses, and industry. The reservoir is a core facility sustaining the development of Makassar, the capital city of South Sulawesi Province located at the mouth of the Jeneberang River, with a population of about 1,200,000.

Many volcanoes around the world have caldera features with steep sidewall and, in many cases, weak bedrock. These features could explain the large-scale landslide called a sector collapse occurred in South Sulawesi. The aim of this paper is to outline the landslide and explain its mechanism of occurrence.

\section{Study site}

\section{Geological Setting}

Mount Bawakaraeng volcano, located at about $60 \mathrm{~km}$ east of Makassar, was repeatedly active during the Quaternary era (Dan and Supriatna, 1982). Some caldera-like depressions are apparent on its western foot (Fig. 1, and 2). In general, a caldera is a volcanic feature formed by the collapse of a volcano into itself, usually triggered by the emptying of the magma chamber beneath the volcano (Gudmundsson, 1988). In some volcanoes the magma feeding the volcano is relatively silica poor, and the magma chamber is drained by large lava flows rather than by explosive events. The resulting calderas are also known as subsidence calderas, and can form more gradually than explosive calderas (references). However, the driving phenomenon at this site is large-scale flank collapse, not associated with magma withdrawal from a reservoir. Because there are no distinct craters and traces of crater lakes in the caldera, it is considered that the caldera-like depressions were created by erosion (Karaston et al, 1999), as seen in the Canary Islands (Masson et al., 2000).

\footnotetext{
1) Faculty of agriculture, Shizuoka University, 836 Ohya, Suruga-ku, Shizuoka-shi 422-8529, Japan (afstuti@agr.shizuoka.ac.jp)

2) Department of Environmental Engineering, Kochi University, Otsu 200, Monobe, Nankoku-shi, Kochi 783-8502, Japan

3) Department of Forest Sciences, Utsunomiya University, 350 Mine, Utsunomioya, 321-8505, Japan

4) CTI Engineering International Co., Ltd, 3-21-1 Hama-cyo, Nihonbashi, Chuo-ku, Tokyo 103-8430, Japan
} 


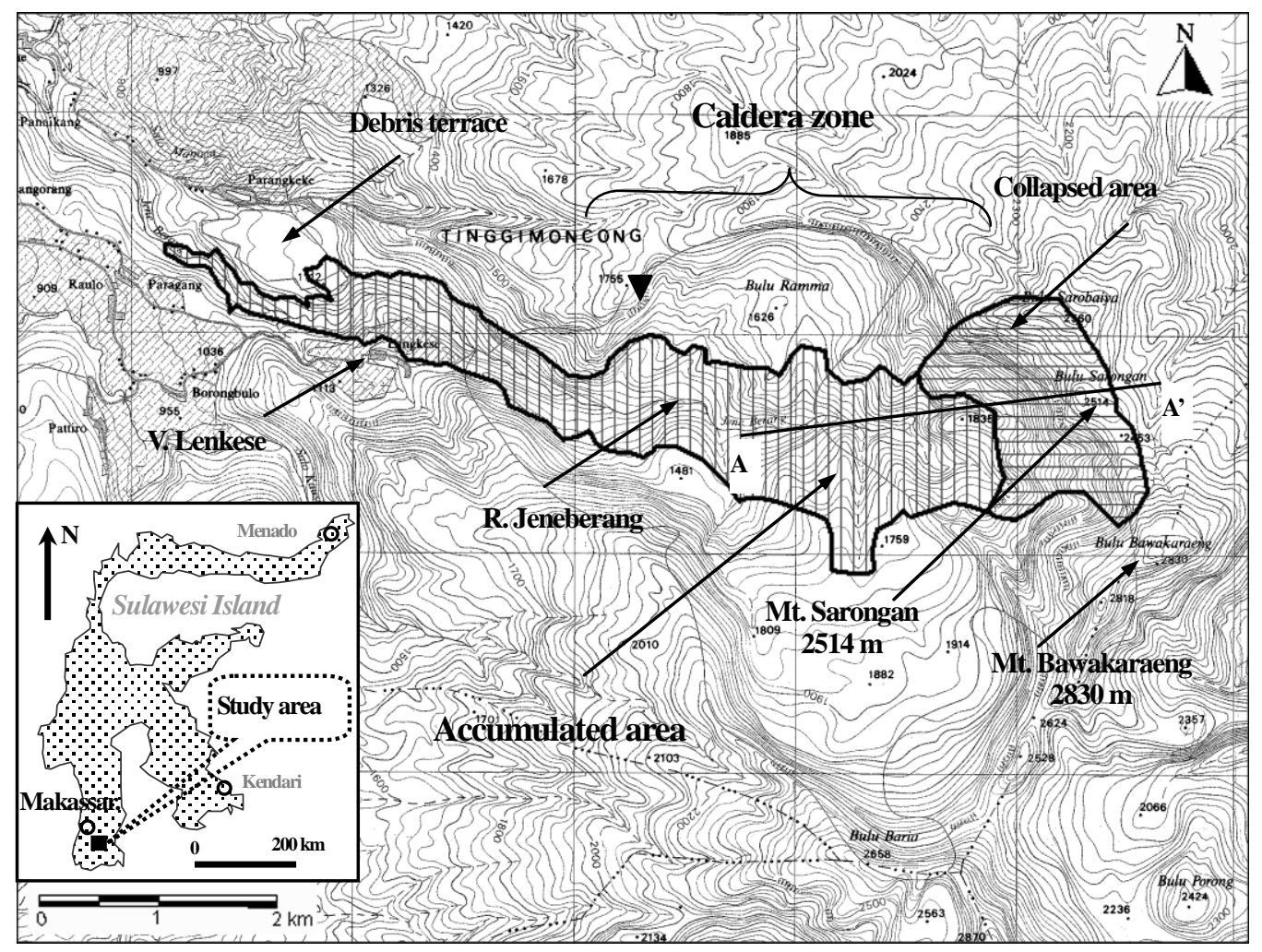

Fig. 2 Location of study site and distribution of debris deposits ( $\mathbf{v}$ shows view site of Fig.1, A-A' line is used in Fig. 5)

The Jeneberang River originates at the northwest foot of Mt. Bawakaraeng, about $2500 \mathrm{~m}$ above sea level, and immediately passes through the calderas as it flows westward (Fig. 2). The caldera, are distinguishable as two desolate circular basins, the one with a $2 \mathrm{~km}$ diameter on south side, and another with a $1.5 \mathrm{~km}$ diameter on the north side. The landslide occurred on the inner side of the northern caldera wall.

There must be a plenty of debris outflow from these calderas through the Quaternary era in accordance with tropical heavy rains. Outside of the caldera, large-scale terraces formed by the past debris flows parallel the river (Fig.1). The uppermost layer of the caldera sidewalls is composed of a layer of basalt layer that flowed out from the volcano to overlie basaltic andesite layer, the pyroclastic deposits, and the tuff (van Leeuwen, 1981). Because the lowermost part of the underlying material is covered with vegetation and talus deposits, its constitution is not clear, but fragmentary deposits at the foot of the caldera walls suggest that it is composed of the same materials as above. The area of a catchment from the toe of the debris avalanche to the divide including calderas is $25.6 \mathrm{~km}^{2}$.

\section{Rainfall}

The climate of Sulawesi Island is tropical. The northeast monsoon brings the rainy season between November and May (with maximum rainfall in December and January), and southwest monsoon brings the dry season between June and October.

Figure 3 shows the monthly average rainfall over 25 years (1978 to 2003) at Malino, about $15 \mathrm{~km}$ northeast of the landslide. The monthly rainfall is more than $700 \mathrm{~mm}$ per month from December to February, and reaches 900 $\mathrm{mm}$ in January. The average annual rainfall is $4424 \mathrm{~mm}$. Under these conditions, the outlet valley from the caldera can maintain its dominant down-cutting position by capturing the runoff from the primary depression to enlarge its drainage basin.

The main cause of the landslide is still unidentified. The cumulative rainfall recorded at Tinggimoncong, near the landslide site, during March 1 to 26 before landslide was $783 \mathrm{~mm}$ (Fig.4). The rain data accumulated for short period at Tinggimoncong, but the March rainfall was about 1.5 times the

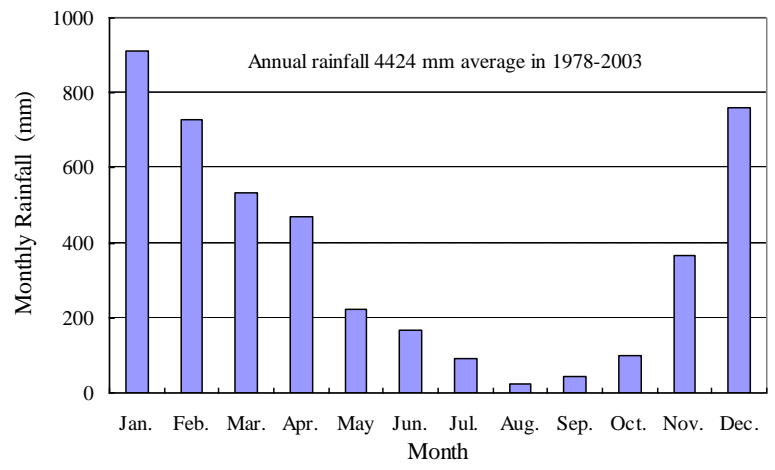

Fig.3 Average monthly rainfall at the Marino from 1978 to 2003

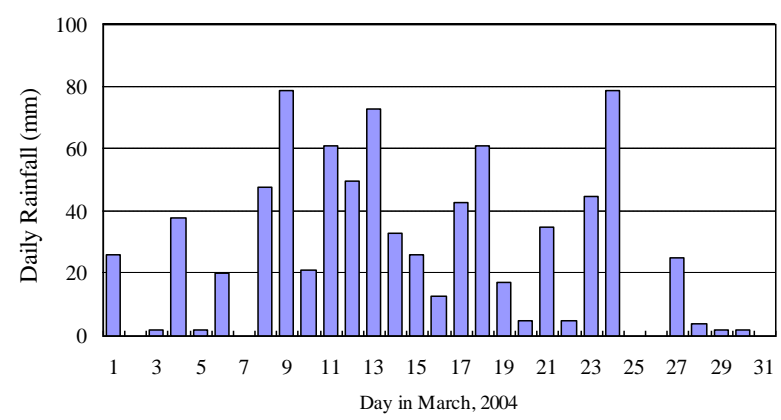

Fig.4 Actual daily rainfalls at Tinggimoncong in March, 2004 


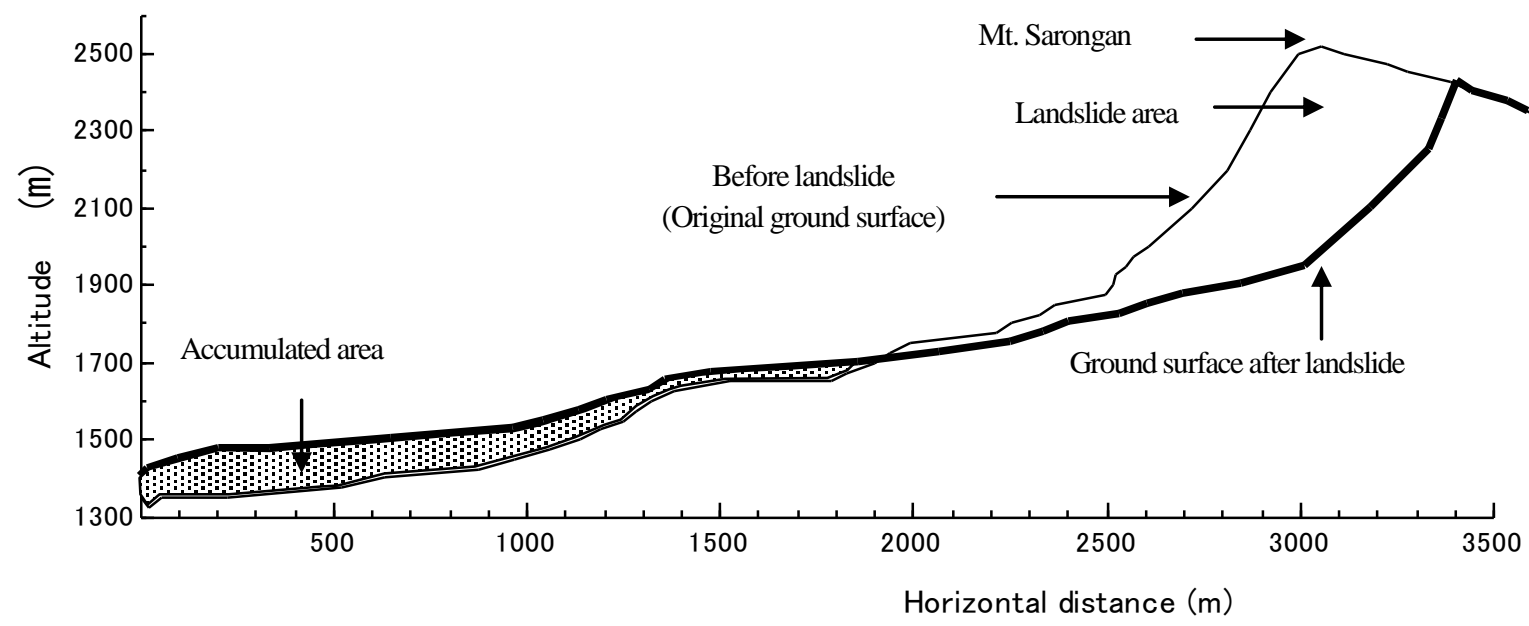

Fig.5 Comparison of the cross-section (line A-A' in Fig. 2) before and after the landslide (the later cross-section was taken from aerial photographs taken in August 2004)

March average of $508 \mathrm{~mm}$ over 20 years at Malino, about $5 \mathrm{~km}$ away. However, no rainfall was recorded on the day of occurrence, March 26, and no earthquakes were not recorded except that due to the landslide at Makassar.

\section{Mechanism of large-scale landslide}

Figure 5 shows a typical cross section (A-A') before the landslide and after the landslide. The landslide originated from the rear side of the ridge (Mt. Sarongan) of about $300 \mathrm{~m}$ to a slope end of $1800 \mathrm{~m}$ above sea level with over $600 \mathrm{~m}$ vertically. The failure surface was a sharp shear with almost the same slope inclination as the old ground surface, and no unstable debris mass on the surface was apparent (Fig. 6).

These facts suggest that the slide occurred remarkably rapidly, and the whole mass fell sharply and uniformly to the bedrock. Therefore, the slope followed a sliding movement, not a toppling movement. Moreover, it is reasonable to suppose that the detached rock mass crashed to the base rock near the toe and crumbled, then flowed as a debris avalanche, as inferred from the distribution of the debris deposit in the caldera.

\section{Stability analysis by Limit Equilibrium method}

Very few studies have evaluated the slope stability of large-scale landslide thicker than $600 \mathrm{~m}$ (Brückl et. al, 2005). In general, if the shearing resistance angle $\left(\varphi^{\prime}\right)$ in a slope is mostly less than $45^{\circ}$, the safety factor $(F s)$ of a deeper slip surface tends to be a larger than that of a shallow slide surface. Many slopes are less than $45^{\circ}$, and may be a result of many shallow landslides caused by downpour and earthquake.

Rock strength information is necessary to better understand initial landslide process. In obtaining the rock mass strength, we need for the classification of the rock mass. As for the rock mass classification and strength criteria, Mohr-Coulomb and Hoek-Brown failure criteria (Hoek, 1983) are widely used in rock engineering, but very few applications have been done in Japan. We classified the rock as grade CL class (Japan Society of Civil Engineers, 1999), in consideration of the geological composition and weathering conditions in the caldera sidewall, and estimated the shear strength parameters of friction angle $\varphi^{\prime}=35^{\circ}$ and cohesion $c^{\prime}=490 \mathrm{kPa}\left(5 \mathrm{kgf} / \mathrm{cm}^{2}\right)$, and unit weight $\gamma t=17.6 \mathrm{kN} / \mathrm{m}^{3}\left(1.8 \mathrm{gf} / \mathrm{cm}^{3}\right)$. Among igneous and the volcanic rocks of rock grade CL, $c^{\prime}$ ranges from 294 to $1079 \mathrm{kPa}$ (average $490 \mathrm{kPa}$ ) and $\varphi^{\prime}$ from $35^{\circ}$ to $44^{\circ}$ (average of $40^{\circ}$ ) (Saito and Katahira, 1983). If the rock type in grade CL is not specified, then $c^{\prime}$ is less than $980 \mathrm{kPa}$, and the angle $\varphi^{\prime}=15^{\circ}$ to $38^{\circ}$ (Japan Society of Civil Engineers, 1999).

The section used for the stability analysis is shown in Fig 7. The limit equilibrium method used in our evaluation of slope stability of the large-scale landslide uses the ordinary method of slices to estimate Fs (Lambe and Whitman, 1969), adjusted with the empirical strength values of friction angle and cohesion. It is written as:

$$
F_{s}=\frac{c^{\prime} L+\tan \varphi \sum_{i=1}^{i=n}\left(W_{i} \cos \theta_{i}-u_{i} l_{i}\right)}{\sum_{i=1}^{i=n} W_{i} \sin \theta_{i}}
$$

where $L$ is the length of the entire slip surface, $W$ is the weight of slice, $u$ is the pore water pressure, $l$ is the length of the sliced-slip surface, subscript $i$ is $i$ th slice, and $n$ is the number of slices. The safety factor computed by this method will be in error. In some cases, from this method may be 10 to $15 \%$ below the range of equally correct answers. However, this method is widely used in practice because of its simplicity, and errs on the safe side (Lambe and Whitman, 1969).

Using the presumed value of $c^{\prime}, \varphi^{\prime}$ and $\gamma t$ we calculated the safety factor $F S$ as 1.59 by the ordinary method of slices without a groundwater table. The rise of groundwater was obvious cause of the landslide, because the 50\% more rain fell in March than the average. As the toe of the landslide slope is the head of the Jeneberang River (about $1850 \mathrm{~m}$ above sea level), underground water likely wells from there. Therefore, it is reasonably to use the groundwater level in the

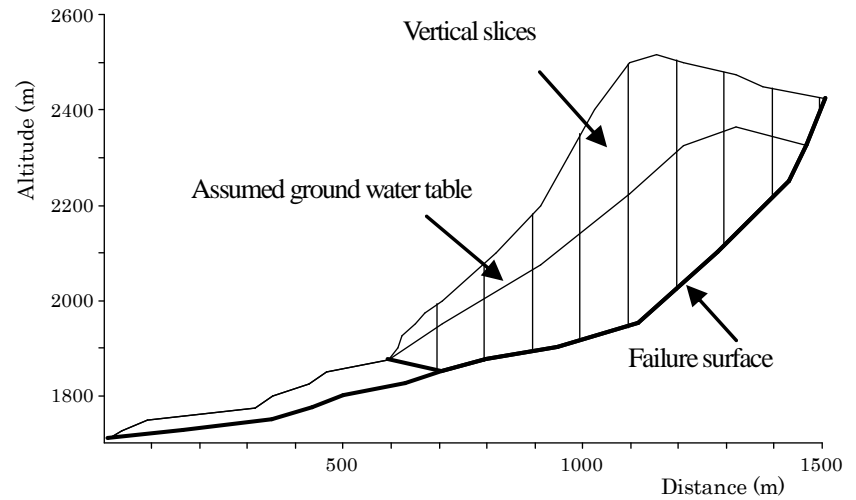

Fig.7 Sliced section for the application of limit equilibrium method 


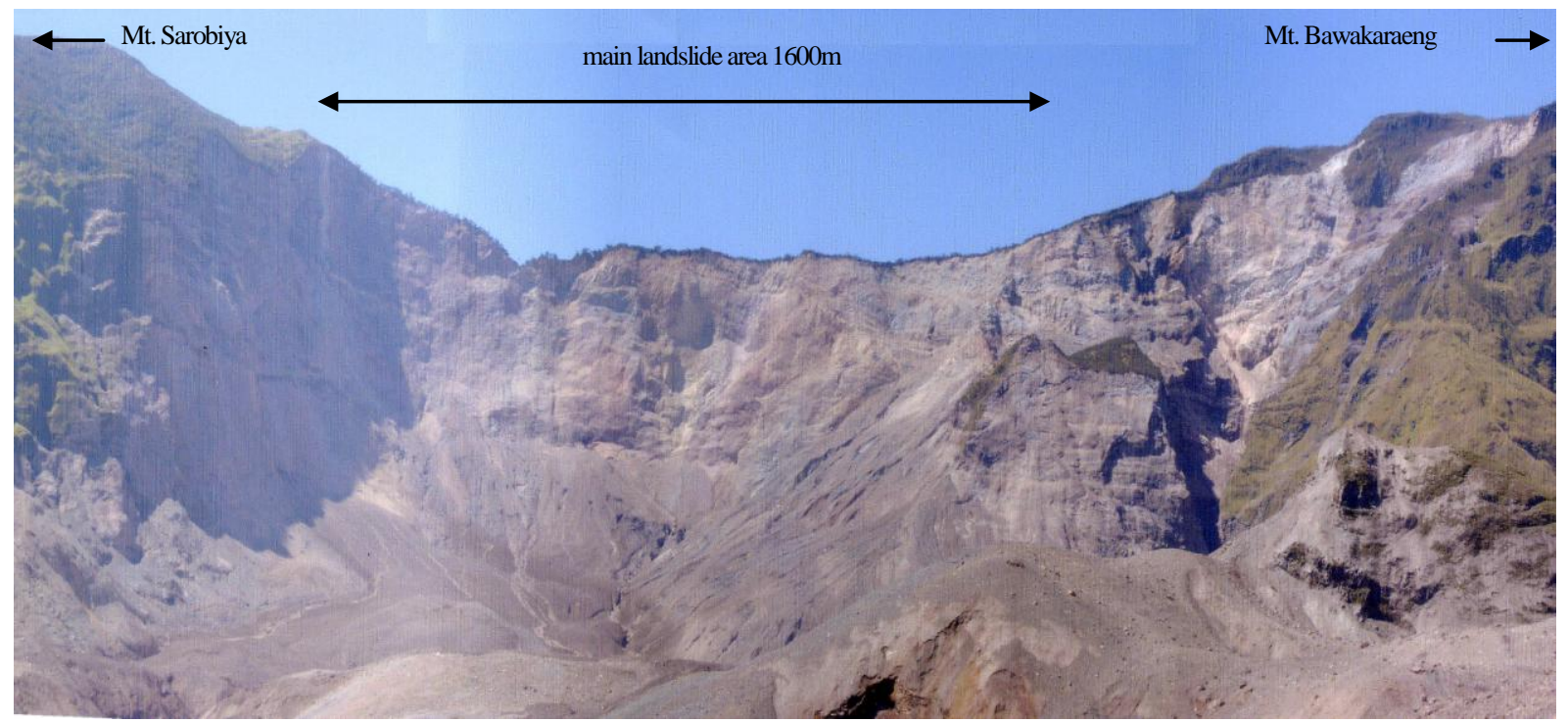

Fig. 6 View of the head of the landslide (2005 September 8)

stability analysis. Executing the stability analysis by trial and error with an Fs value up to 1.0, we obtained the groundwater level shown in Fig.7.

\section{Stability analysis by SSRFEM}

Our great interest is whether the shear strain and displacement in the surrounding of slip surface had had a unique value before the landslide and the critical slip surface was predictable. Slope fails because of its material shear strength on the sip surface is insufficient to resist the actual shear stress. In accordance to the shear failure, the value of $F s$ opposing slope failure is simply calculated as:

$F_{s}=\tau / \tau_{f}, \quad \tau=c^{\prime}+\sigma_{n} \tan \phi^{\prime}, \quad \tau_{f}=c_{f}^{\prime}+\sigma_{n} \tan \phi_{f}^{\prime}$

Where $\tau$, the shear strength of the slope material, is calculated according to Mohr-Coulomb criterion with the normal stress $\sigma_{n}$, cohesion $c^{\prime}$, and the internal friction angle $\varphi^{\prime}$. And $\tau_{f}$ is the shear stress on the sliding surface. It can be calculated with the factored shear strength parameters $c_{f}^{\prime}$ and $\varphi_{f}^{\prime}$, which are given by:

$$
c_{f}^{\prime}=c^{\prime} / F_{r}, \phi_{f}^{\prime}=\arctan \left(\tan \phi^{\prime} / F_{r}\right)
$$

where $F r$ is the strength reduction factor. This method is referred to as the "Shear strength reduction technique" (Matsui and San, 1992).

We conducted stress-strain analysis by the SSRFEM method (Japan Geotechnical Society, 2003) to calculate the shear strain and displacement before the landslide, and to obtain information on the collapse generation. The method uses the strength reduction factor in the same way as follows. To achieve the correct $F r$, it is essential to trace the value of $F s$ that will just cause the slope to fail. Non-convergence within a number of iteration in finite element program is taken as a suitable indicator of slope failure (Zienkiewicz et al., 1975; Ugai, 1989). This means that no stress distribution can be achieved to satisfy both the Mohr-Coulomb criterion and global equilibrium. The strength reduction factor $\mathrm{Fr}$ at this time is almost equal to the safety factor $F s$ of the entire slope, and the position of a critical slip surface under the state is given from the distribution of the maximum shear strain immediately before failure (Ugai, 1995; Griffiths and Lane, 1999).

Figure 8 shows the results with a dilatancy angle of $\psi=0$, Poisons's ratio $v=0.3$, and Young's modulus $E=1471 \mathrm{Mpa}\left(15000 \mathrm{kgf} / \mathrm{cm}^{2}\right)$, referring the empirical data of the rock classification CL. The shear strength parameters $c$ ' and $\varphi$ ', unit weight $\gamma t$ are the same in the limit equilibrium method. According to Fig. 8, the distribution of the maximum shear strain $(\boldsymbol{A})$ lies along a shallower location in an arc shape than the position of the actual slip surface $(\boldsymbol{C})$. In the central slope, the relatively large shear strain $(\boldsymbol{B})$ is intensive, although an arc-shaped distribution is not clear. Arc (A) in the latter is treated as a critical slip surface below, because the distribution of the strain in the former shows an obscure arc shape with poor continuity. The ground stress around the toe of $(\boldsymbol{A})$ is interesting around the toe of landslide. Also, it is interesting what level of the stress is generating at around the toe of $(\boldsymbol{A})$. The stress value at the white circle in Fig. 8 ranged from 1.53 to $2.33 \mathrm{MPa}$ in the $x$ direction, from 2.17 to $3.28 \mathrm{MPa}$ in the $y$, and from 4.12 to 4.93 MPa in the $z$.

We did not take into consideration the weathering degree of the caldera wall inside in the stability analysis by SSRFEM, because of having no effective information. Although the progression of weathering into the slope had to be foreseen for applying, the degree is also not homogeneous. However our assumption of uniform ground composition could explain the shallower critical slip surface than the actual slip surface. Although we have no effective information, the progression of weathering into the slope can be easily foreseen, and the degree is not homogeneous. After all, if information on properties of the ground on the slope is accurate, the critical slip surface predicted by SSRFEM analysis will be close to the actual slip surface, because the end positions of the slip surface on the ground and in the analysis were almost the same. Moreover, the end position of the critical slip surface before the landslide was a knick point at which the slope inclination was steeper, and was the headwater of the Jeneberang River.

Thus, we can propose a primary geomorphologic cause of the large-scale landslide, considering that the knick point formed at the end of the critical slip surface, and the predicted location is equivalent to the end of the actual slip surface.

The vertical compression displacement shows about $3 \mathrm{~m}$ subsidence overall on the ridge (Fig.8). As for a horizontal displacement, it indicates that the deflection of about $30 \mathrm{~cm}$ from the toe of landslide to the about $200 \mathrm{~m}$ horizontal distance in the direction of the original caldera wall side. Therefore, the horizontal position that is $200 \mathrm{~m}$ to $300 \mathrm{~m}$ from the toe surface of landslide is bending in the direction of slide, and the bending transformation tends to concentrate on the end of the slip surface. But the amount of the bending transformation does not reach to the destruction of the ground rock, and 


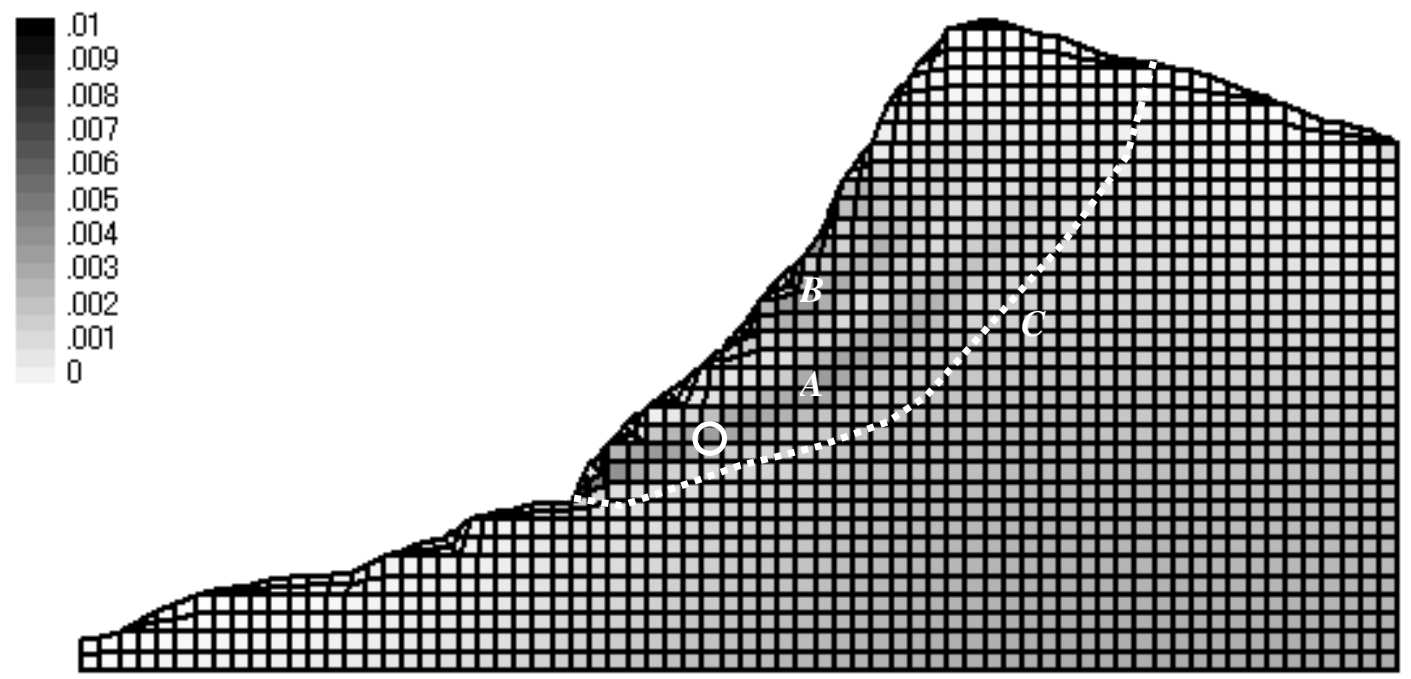

Distance 1750 m

Fig.7 Distribution of shear strain by the SSRFEM (White circle is the point which shows stress values in this paper, $A$ and $B$ show distribution of maximum shear strain, $C$ shows actual sliding surface)

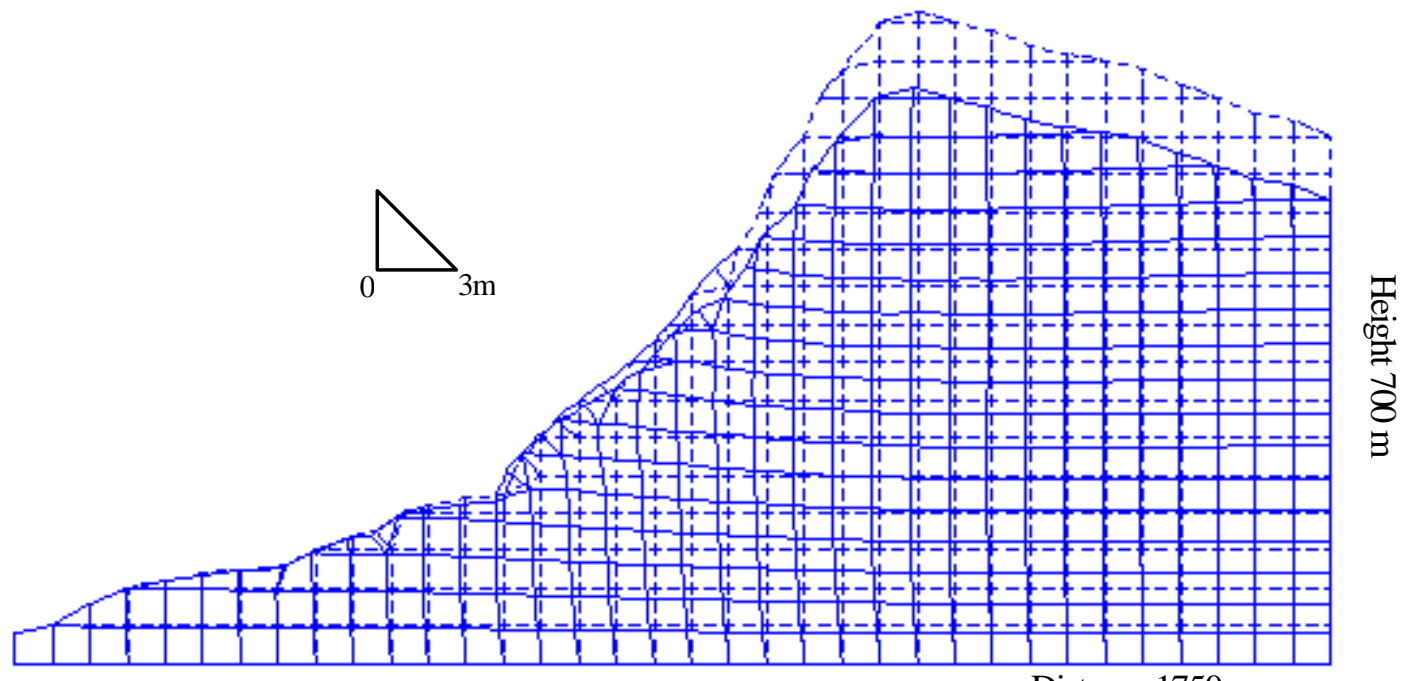

Distance $1750 \mathrm{~m}$

Fig.8 Distribution of total displacement by the SSRFEM (solid line shows the calculated, broken line shows the original terrain

does not form the slip surface, because of the value of strain at the position is in the range of elasticity.

The overall safety factor corresponding to the critical slip surface (A) was 1.19 by SSRFEM but 1.59 (without groundwater) by the limit equilibrium method. We considered that the difference was due to the different position of the slide surface, and the use of the zero dilatancy angle and the non-associated flow rule in both analyses (Japan Landslide Society, 2006). The SSRFEM method gave a shallower critical slip surface than the actual slip surface, but the result is acceptable, considering the lack of information on the degree of rock weathering and the ground properties. For the future, we would like to improve the SSRFEM with information on the geologic structure beneath the ground.

\section{Conclusions}

Increased population has placed large numbers of people within range of major volcanic landslides. There is a large possibility that a large-scale collapse in a densely populated region would cause a great disaster. The caldera at our study site is representative a great number of calderas around the world. We studied the mechanism that generated the landslide on the caldera wall of Mt. Bawakaraeng, South Sulawesi, Indonesia. We drew the following conclusions from the field investigation, stability analysis, and the shear strain analysis by SSRFEM.

- The caldera-like depressions on the western foot of Mt. Bawakaraemg were created by erosion. The main cause of the landslide is still unidentified, but a rise of ground water in the caldera wall would have been a major trigger.

- Slope stability analysis by the limit equilibrium method supports this theory.

- The critical slip surface obtained by the SSRFEM was shallower than the actual slip surface, but the toe positions were in the same location, SSFEM 
analysis is useful for evaluating the stability of a large-scale landslide.

- It is likely that the knick point was formed by erosion by the Jeneberang River was a geomorphologic cause of the landslide, because the toe of the critical slip surface, the knick point, and the toe of the actual slide-surface were all in the same position.

The SSRFEM analysis presented here could be useful for evaluating the slope stability of large-scale landslides, because the predicted critical slip surface is mostly the same as the actual surface, even though the analysis assumed homogenous conditions without information on the degree of weathering and ground properties.

\section{Acknowledgements}

We conducted the site investigation as a JICA Sabo urgent investigation during 2004 June 20 to 29. We would like to acknowledge JICA (Japan International Corporation Agency) for giving us the opportunity, and are grateful for the cooperation and help extended to us by the NGO, Komunitas

Sabo. Especially, we would like to thank Dr. Agnes (Hasunudin University, Makassar) for helping in the site investigation. This study was supported by a grant-in-aid for research from the Ministry of Education, Science and Culture of Japan (Project No: 1740503).

\section{References}

Brückl, E. and Parotidis, M. (2005) Prediction of slope instabilities due to deep-seated gravitational creep. Natural Hazards and Earth System Science, 5: $155-172$.

Dan, R. S. and Supriatna, S. (1982) Geologic map of the Ujungpandang, Benteg and SinJai Quadrangles, Sulawesi. Geological Research and Development Centre, Bandung, Indnesia.

Griffiths, D.V. and Lane, P.A. (1999) Slope Stability analysis by finite elements. Géotechnique, 49(3):387-403.

Gudmundsson, A. (1988) Formation of collapse calderas, Geology, 16:808-810.

Hoek, E. (1983) Strength of jointed rock masses, 23d. Rankine Lecture. Géotechnique, 33(3) 187-223.

Hürlimann, M., Ledesma, A. and Martj, J. (1999) Conditions favoring catastrophic landslide on Tenerrife (Canary Islands), Terra Nova, 11(2/3):106-111.

Japan Landslide Society (2006) Landslide analysis by finite element method. SANKAIDO, Tokyo, pp.131.

Japan Society of Civil Engineers (1999) Site investigation and stabilization methods for rock slopes. Japan Society of Civil Engineers, Tokyo, pp. 124.

Japan Geotechnical Society (2003) Use the Elasto-plastic Finite Element Method, Japan Geotechnical Society, Tokyo, pp.314.

Karaston D., Thouret, J. C., Moriya, I., Lomoschitz A. (1999) Erosion calderas: origins, structural and climatic control. Bulletin of Volcanology, 61:174-193.

Lambe, T.W. and Wiitman, R.V. (1969) Soil Mechanics. John Wily \& Sons, New York. pp.553.

Masson, D. G. Watts, A. B., Gee, M. J. R., Urgels, R., Mitchell, N. C., Le Bas, T. P., Canals, M. (2000) Slope failures on the flanks of the western Canary Islands. Earth-Science Reviews, 57:1-35.

Matsui, T. and San K-C. (1992) Finite element slope stability analysis by shear strenrth reduction technique, Solis and Foundations, 32(1):59-70.

Moon, V. and Simpson, C. J. (2002) Large-scale mass wasting in ancient volcanic materials, Engineering Geology, 64:41-64.

Rocscience Inc. (2002) Application of the Ffinite element method to slope stability. Rocscience Inc., Toronto, pp.57.

Saito, k. and Katahira, H. (1983) Some consideration on measured value from in-situ rock test of dam foundation. Technical note No. 1899, Pubic Works Research Institute, Ministry of Construction, Japan, pp.78.

Siebert, 1. (1992) Threats from debris avalanches, Nature, 356(23):658-659.

Tsuchiya, S. Koga, S., Sasahara, k., Matsui, M., Nakahiro, M., Watanabe, H., Shima, H., Yoshida, K. (2004) Reconnaissance of the gigantic landslide occurred on Mt. Bawakaraeng in the south Sulawesi state of Indonesia and unstable debris sedimentation (prompt report). Journal of the Japan Society of Erosion Control Engineering, 57(3):40-46.

Ugai, K. (1989) A method of calculation of total safety factor pf slope by elasto-plastic FEM, Soils and Foundation, 29(2):190-195.

Ugai, K. and Leshchinsky D. (1995) Three-dimensional limit equilibrium and finite element analysis: A comparison of results, Soils and Foundation, 35(4):1-7.

van Leeuwen, Th. M. (1981) The geology of south Sulawesi with special reference to the Biru area. The Geology and Tectonics of Eastern Indonesia, Geological research and Development Centre, Bandung Indonesia, 2:277-304

Zienkiewicz, O. C., Humpheerson, C. and Lewis, R. W. (1975) Associated and non-associated visco-plasticity and plasticity in soil mechanics, Géotechnique, 25(4):671-689. 